\title{
EVALUATE THE EFFECT OF PERCEIVED EASE AND USEFULNESS,CUSTOMER'S AWARENESS AND CONFIDENCE BY MOBILE BANK ON TENDENCY TO USE (INTENDED USE) OF MOBILE BANK'S SYSTEM (CASE STUDY OF CUSTOMERS OF KHUZESTAN'S TEJARAT BANKBRANCHES)
}

\author{
H. Zeinabi ${ }^{*}$ and M. Sheikh
}

Master, Ahvaz Branch, Islamic Azad University, Ahvaz, Iran

Published online: 18 July 2016

\begin{abstract}
The aim of present research is study of ease and perceived usefulness, customer's awareness and confidence to mobile bank on tendency to use of mobile bank's system. In terms of purpose is applied and in terms of the nature and methods is casual. Questionnaire has been used to collect the required data of. 24 items has been raised in the questionnaire. Questionnaire has sufficient reliability and validity. Statistical population of research the customers of Tejarat Bank branches in Khuzestan province that are used from mobile banking (mobile banking), Principles of determine the sample size in the sample of multivariate regression analysis has been used in structural equation modeling. The method of sampling is clustered and total of 300 questionnaires were distributed that finally the 274 questionnaires were completed and were analyzed. Structural equation modeling has been used to study the relationships between model's components and LISREL software has been used for Analysis of hypotheses. Results show that awareness has positive impact on tends to use of mobile bank. Usefulness has positive impact on tend to use of mobile bank. Ease has positive impact on tend to use of mobile bank. Trust to technology has positive impact on trust to mobile bank. Security has positive impact on trust to mobile bank. Information's quality has positive impact on trust to mobile bank.

Author Correspondence, e-mail: hassanzeinebi2@gmail.com

doi: http://dx.doi.org/10.4314/jfas.v8i2s.125
\end{abstract}

Journal of Fundamental and Applied Sciences is licensed under a Creative Commons Attribution-NonCommercial 4.0

International License. Libraries Resource Directory. We are listed under Research Associations category. 
Trust to mobile bank has positive impact on tend to use of mobile bank.

Keywords: Trust to technology, Security, Awareness, Usefulness, Information's quality

\section{INTRODUCTION}

Broad and deep impact of electronic commerce on global markets in the last few decades on the one hand and the importance and role of monetary and credit. In trade and economic activities on the other hand The necessity of providing platforms and Necessary facilities in facilitating the transfer and Currency exchange make necessary more than ever technologies like internet banking, phone banking and mobile banking in recent years, are rampant as methods for maintaining customer's loyalty and increase market's share (Konjkav monfared \& Mir hoseini, 2013). Mobile Bank is one of the technological wonders of Mobile and is one of the recent innovations in the financial services sector and make enables customers to gain easy access to value-added and banking services even in countries with low-income (mohamadi, 2015)

In Iran More banking affairs are done through acceleration's system. acceleration or network's information exchange between banks that is a network's comprehensive electronic that is focused on banking in Iran and acceleration or network's information exchange between banks that is a network's comprehensive electronic that is focused on banking in Iran And has been started and managed by the Central Bank of the Islamic Republic of Iran .In various areas of activities serves, such as exchange, payments, online shopping, money transfers, bills, check account. Design of this network is so that helped to customers in using the services of banks at non-office hours and in 24 hours (hanafi zade et al, 2014\& mohammadi, 2015)

According to the statistics' of central bank more than 7 billion and 110 million pieces of notes used in Iran that in this regard Iran has available for the first Place in the world. The most important feature that can be considered for e-banking, communicate quickly with all audiences and provide services is based on the each person's needs. Now that on the one hand the country's banking system has believed using electronic means in the banks and is determined for implement the relevant executive regulations and also on the one hand the lack of timely provide banking services through the banking system as a major obstacle in the direction of expansion of bank's services and as a result is considered the country's economic development (Amadeh \& Gafari poor,2008)Bank of commerce as one of the largest trade's banks of area with the design and creation of new services and With the aim to create value for customers, especially valuable 
customers, has an effective presence in the domestic, regional and global markets. Bank's credit and reputation along with skilled man power and also capability of provide banking services especially in the field of obligations has been provided this possibility for bank until in the framework of country's monetary and banking laws, Meanwhile promotion of profitability and supply interests of all beneficiaries can play effective role in economic development and progress of the country's banking system.

\section{The theoretical framework and conceptual model of research}

Electronic payment help to automation payments and receipts and as a result cause to reducing and eliminating the high costs of paper And human resources and potential errors in the processing and it also allows to allotment better resources and improved forecast of cash flow and as a result cause to improved cash flow and increase productivity, profitability and business agility (Amran et al, 2014).

According to Lee et al (2015),mobile bank is development of financial and bank and networks and mobile devices services. Properties such as time, no need to place, to same measure Secure Exchange through the use of personal mobile with specified User account or owner and consolidation and impact of the transaction that will lead to the rapid growth of mobile bank.

A general approach to the study of mobile bank is focused on customer behavior. Studies that use this method, studding dispersion of patterns and demographic characteristics of recipients of mobile banks ,prohibitions and Stimulants, received risks from mobile bank, Customer attitude, behavioral intention to use of services(Lee et al 2015), Alone et al (2013) studied of user satisfaction from E-government services. The results showed that security and confidence to egovernment no impact on satisfaction. Access to e-government portal, quality of services and awareness from services has effect on satisfaction of electronic.

Lynn in 2013 in his Research conducted determine of relative importance of qualitative factors of mobile bank. The aim of the study was using from The phase analytic hierarchy process by Extensive analysis method of The phase evaluation model and the relative weights prioritized the qualitative factors of mobile bank between the groups with experienced and inexperienced .

Masker et al (2014) studied the relationship between trust to technology and satisfaction of mobile bank the results showed that trust to technology has positive and Meaningful relationship with satisfaction from mobile bank. Abu-Shenab (2014) in his Research he studied Backgrounds of Trust to e-government services in Jordan. 
The results showed that all of the suggested variables in the model of trust to e-government with the exception of familiarity with the Internet have positive impact on the inclination to use egovernment. Trust to e-government, simplicity, usefulness, social impact, has positive impact on the inclination to use e-government.

Mahammadi (2015) conducted study regarding of loyalty to mobile bank in Iran. The purpose was obstacle detection, moderating role of benefit and moderating role of person's innovation and subjective norms on consumer attitudes in the direction use from mobile bank in Iran.

Konjkav monfared \& mir hoseini (2013) studied Effective factors on the reception of mobile bank by customers of Yazd city's export bank branches. . The results showed that the identified factors in model has the direct or indirect effect on the actual use of user's from mobile bank that through received benefits contract in the first rank. Hashemian \& isaiee (2011) studied and identified key factors critical in acceptance of mobile bank by the customers The results showed that factors of service's quality ,trust to bank, expected operation, adaptation of duty-technology, effort expected, facilitating conditions, information about services, self-efficacy and person's innovation have a significant impact on the acceptance of mobile bank.

Variables of ease, usefulness and awareness are in independent variables that will be study their impact on tend to use from mobile bank services. also trust to technology, quality of information and security are independent variables that their impact has been studied with trust to the mobile bank (mediator variable ) and Eventually impact of mediator variable ,trust to mobile bank has been studied on tend to use of mobile bank services (intended of use).

The conceptual model of research has been shown in Figure 1. 


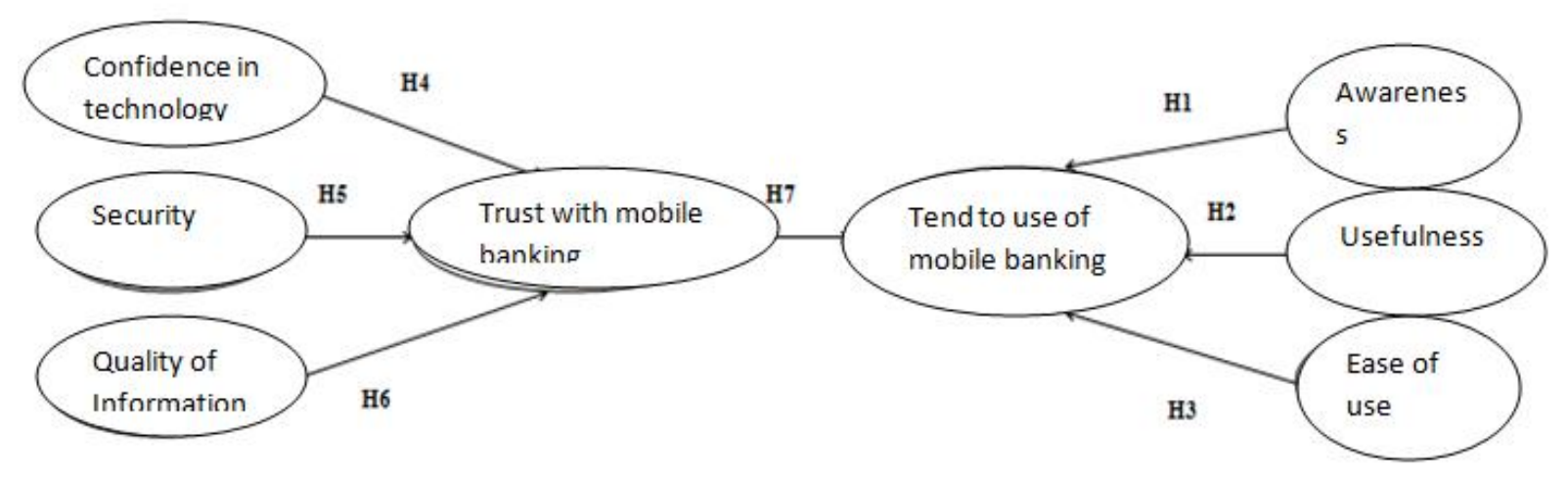

Fig.1. The conceptual model of research

Source: Abu-Shenab (2014) \& Mohammadi (2015)

The first hypothesis: awareness has positive impact on tend to use of mobile bank

The second hypothesis: Usefulness has positive impact on tend to use of mobile bank. (Intended of use)

The third hypothesis: Ease has positive impact on tend to use of mobile bank. (Intended of use)

The fourth hypothesis: Trust to technology has positive impact on trust to mobile bank.

The fifth hypothesis: Security has positive impact on trust to mobile bank.

The sixth hypothesis: Quality of information has positive impact on trust to mobile bank.

The seventh hypothesis: Trust to mobile bank has positive impact on tend to use of mobile bank. (Intended of use)

\section{RESEARCH METHODOLOGY}

The method of performing this research due to aim is applied and nature of the subject and executive ability of that is casual that this method has been used order to study of Cause and effect's relationship between the variables of research. Statistical society of present research has been considered customers of Khuzestan's Tejarat Bank. For select sampling method has been used from cluster sampling method

To determine the sample size in modeling of structural equation, the methodology of structural equations to a large extent is similar to with some aspects of multivariate regression. Therefore, the principles of determine the sample size has been used in multivariate regression analysis for determine sample size in modeling of structural equation. The sample size in methodology of 
structural equation's modeling can be determined between 5 and 15 observation for each variable Measured

$5 \mathrm{q}<\mathrm{n}<15 \mathrm{q}$

$\mathrm{Q}$ is the number of observed variables (Inventory items) and $\mathrm{n}$ is sample size (Ghafari ashtiani, 2008)

The method of collecting information has been considered as questionnaire in this research.In total 300 questionnaires was distributed among members of Statistical Society and finally we recollected 274 questionnaires and was based as measurement and analysis

The questionnaire consisted of 24 questions five's option prepared for measure of awareness variables, usefulness, ease, trust to technology, security, quality of information, tend to use of mobile bank, trust to mobile bank. It was considered question 4 to 6 variable of usefulness and questions 7 to 9 variable of ease.

Question 10 to 12 Related to trust to Technology, 13 to 15 Related to Security and from question 16 to 18 variable of information's quality, is related to questions of 19 to 21 Related to variable of tend to use of mobile bank, 22 to 24 is related to variable of trust to mobile bank.

In the questionnaires Comments of the respondents has been measured by use of 5-point Likert's spectrum .In present research has been used of Standard questionnaire's research of AbuShenab (2014) \& Mohammadi (2015) ,This questioner are confirmed and used by a group of teachers and experts and thus can be confirmed in terms of validity.

For ensure of no ambiguity in the questions of questionnaire was Distributed sample experimental between 30 person of society people and was used of Cronbach's alpha's method $(\alpha)$ for determine Reliability coefficient of questionnaire by SPSS software and such has been shown in Table 1 , the number of that has been obtained $0 / 805$ that this number indicates the validity coefficient is desirable.

For the data analyze and study of relationship between independent and dependent variables has been used of analysis of Structural Equation's Model and LISREL software. 
Table 1. Reliability of the questionnaire

\begin{tabular}{|c|cc|}
\hline $\begin{array}{c}\text { Reliability } \\
\text { coefficient } \\
\mathbf{0 . 8 3 1}\end{array}$ & research variables & Row \\
\hline $\mathbf{0 . 7 6 7}$ & Usefulness & 1 \\
\hline $\mathbf{0 . 7 9 5}$ & Ease & 3 \\
\hline $\mathbf{0 . 8 2 5}$ & $\begin{array}{c}\text { Reliance on } \\
\text { technology }\end{array}$ & 4 \\
\hline $\mathbf{0 . 7 6 5}$ & $\begin{array}{c}\text { Security } \\
\text { Quality of } \\
\mathbf{0 . 8 6 4}\end{array}$ & 5 \\
\hline $\mathbf{0 . 7 5 2}$ & $\begin{array}{c}\text { Information } \\
\text { Tend to use of } \\
\text { mobile banking }\end{array}$ & 7 \\
\hline $\mathbf{0 . 8 0 3}$ & $\begin{array}{c}\text { Trust with mobile } \\
\text { banking }\end{array}$ \\
\hline
\end{tabular}

\section{Analysis of data}

For measure of demography situation, were raised 3 questions for intended sample. Results showed that about 62.8 percent men and 32.1 percent are women, also, 5.1 percent of respondents did not answer to this question for measure of demography situation, were raised 3 questions for intended sample. Results showed that about 62.8 percent men and 32.1 percent are women, also, 1.5 percent of respondents did not answer to this question. About of age variable more of respondents with 3.26 percent are in age of 40 to 45 years.

Least of respondents with 7 percent are in age less than 25 years. Also, 2.9 percent of respondents did not answer to the question among Levels of schooling diploma, associate degree, bachelor's, master's and higher level ,or Diploma level and Under Diploma most share equivalent to 37.2 percent and the smallest share is related to associate degree level equivalent to 11.3 percent.

In section of inferential analysis of research amounts of Fitting indexes calculated by LISREL software table 2 and also the standardized coefficients and t amounts of structural model has been shown in Figure 2 and3. 
Table 2. Fitting indexes of research's model

\begin{tabular}{|cc|}
\hline Value & $\begin{array}{c}\text { Fitting indexes } \\
\text { Degrees of Freedom }\end{array}$ \\
\hline 465.54 & Chi-Square \\
\hline 2.02 & $\chi^{2} / d f$ \\
\hline 0.91 & NFI \\
\hline 0.94 & NNFI \\
\hline 0.95 & CFI \\
\hline 0.95 & IFI \\
\hline 0.050 & RMR \\
\hline 0.061 & RMSEA \\
\hline 0.88 & GFI \\
\hline 0.84 & AGFI \\
\hline
\end{tabular}

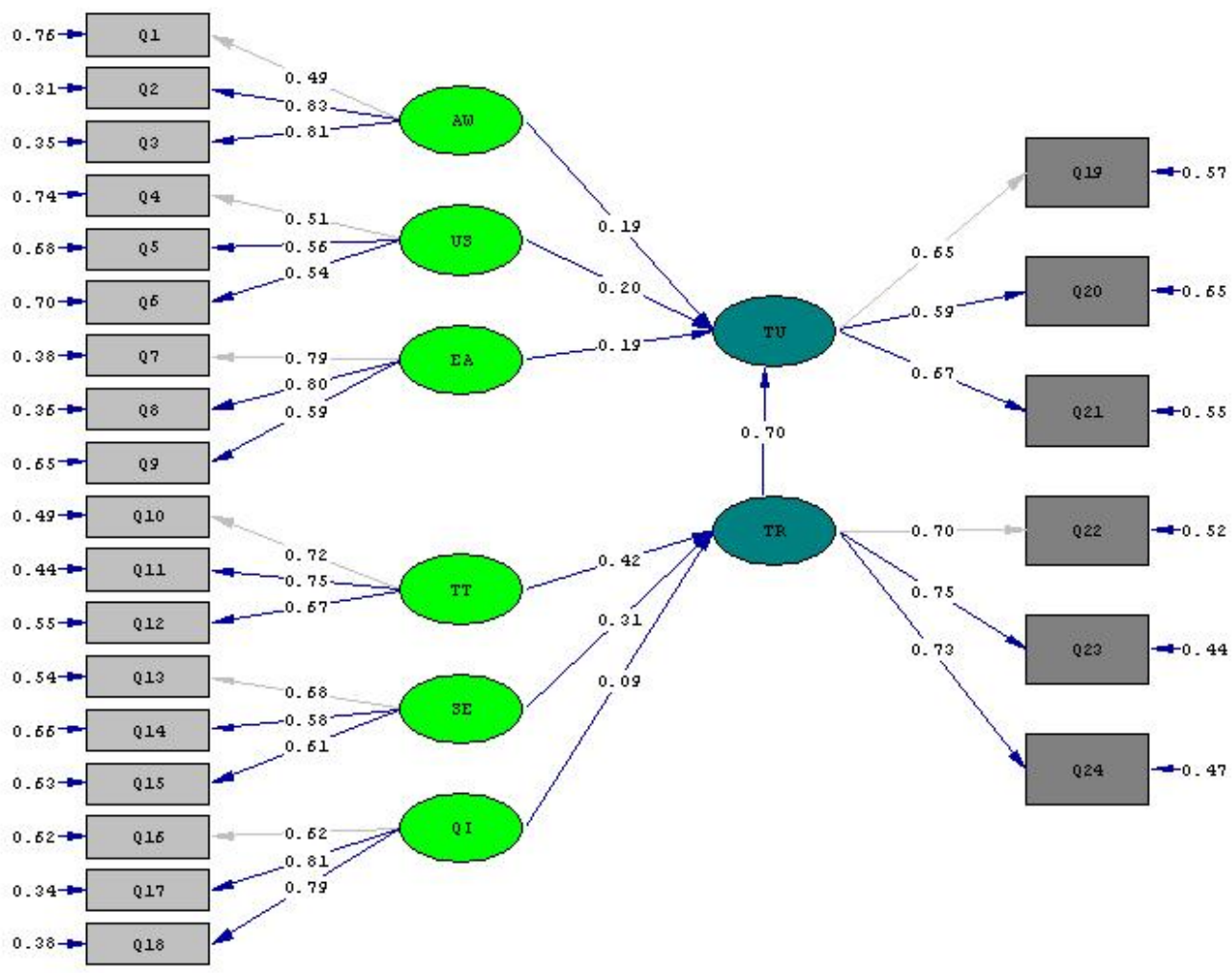

Chi-Squar $e=465.54, d f=230, P-v a l u e=0.00000, \quad$ RMSEA $=0.061$

Fig.2. The standardized coefficients of Structural and measurement model 


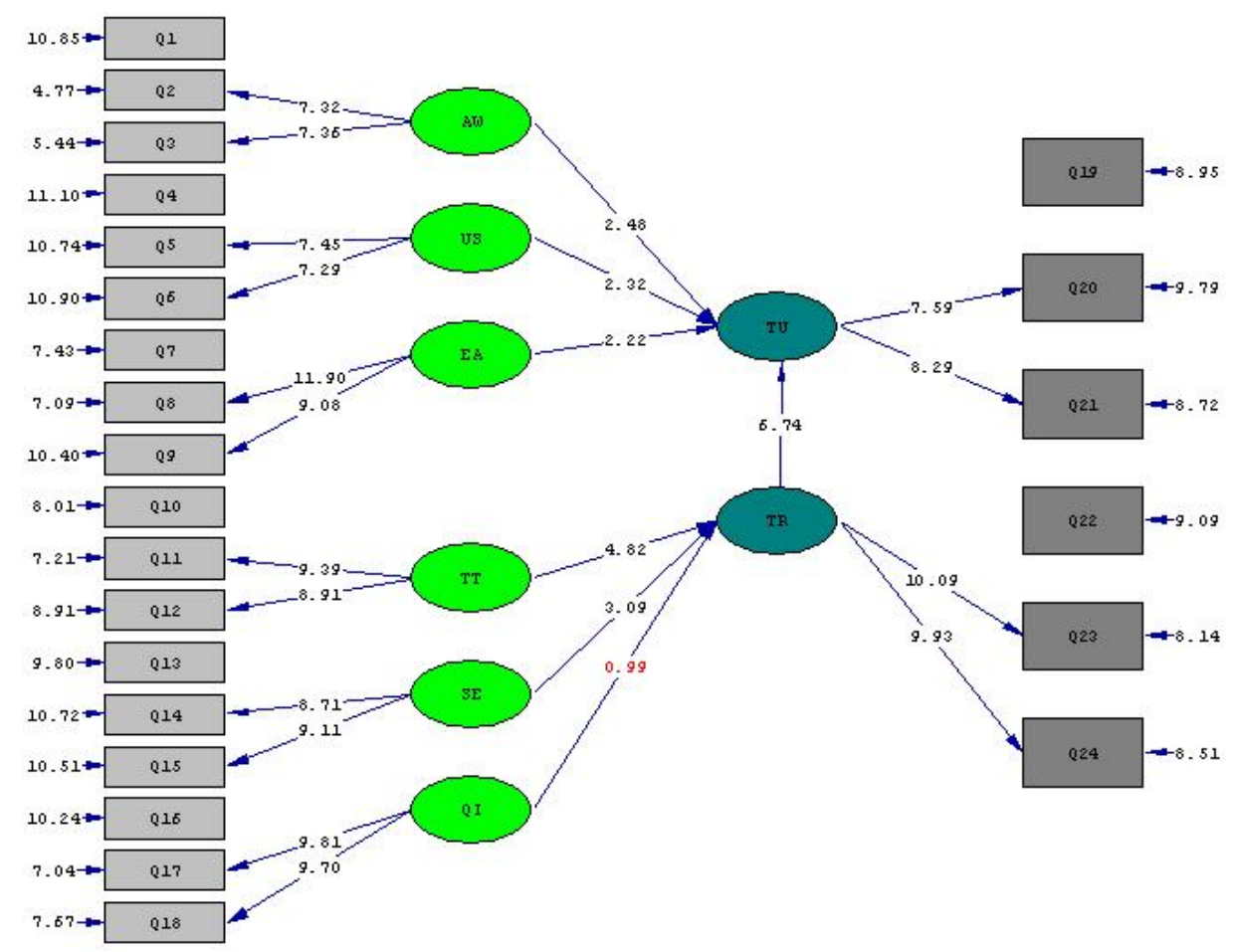

Chi-Squar e $=465.54, d f=230, P$-value $=0.00000, \quad$ RMSEA $=0.061$

Fig.3. Amounts of t-Statistics of Structural and measurement model

The Results of hypotheses has been provided briefly in Table 3

Table 3. Summary of the results of hypotheses test

\begin{tabular}{|c|c|c|c|c|}
\hline Row & hypothesis & Coefficient & $\mathrm{t}$ & Result \\
\hline 1 & Knowledge has a positive impact on the willingness & 0.62 & 5.07 & Confirmation \\
\hline 2 & to use mobile banking. & 0.05 & 0.32 & of hypothesis \\
\hline 3 & Usefulness has a positive impact on the willingness to & 0.46 & 2.86 & Confirmation \\
\hline 4 & use mobile banking. & 0.5 & 4.24 & of hypothesis \\
\hline 5 & Ease has a positive impact on the willingness to use & 0.29 & 2.65 & Confirmation \\
\hline 6 & mobile banking. & 0.34 & 3.33 & of hypothesis \\
\hline 7 & $\begin{array}{l}\text { Reliance on technology has a positive impact on } \\
\text { confidence mobile banking. } \\
\text { Security has a positive impact on trust to use mobile } \\
\text { banking. } \\
\text { The quality of information has a positive impact on } \\
\text { confidence of mobile banking. } \\
\text { Confidence has a positive impact on the willingness } \\
\text { to use mobile banking }\end{array}$ & 0.82 & 6.19 & $\begin{array}{l}\text { Confirmation } \\
\text { of hypothesis } \\
\text { Confirmation } \\
\text { of hypothesis } \\
\text { Rejection of } \\
\text { Hypothesis } \\
\text { Confirmation } \\
\text { of } \\
\text { hypothesis }\end{array}$ \\
\hline
\end{tabular}




\section{CONCLUSION}

According to amounts of t-statistic that is $48 / 2$ awareness have Meaningful impact on tend to use of mobile bank system. On the other hand the raised route between 2 variables of awareness and tend to use of mobile bank system Due to the, is between an independent variable and a dependent variable, isthe kind of gamma and is Meaningful and Positive. The results obtained of this Hypothesis in this research, is parallel with the results of the Mohammadi (2015) research In the present research awareness has been defined as the first factor affecting on use of Mobile bank .Lack of awareness and lack of information about Mobile Bank is important and strong Deterrent in Adoption and use of Mobile Bank. Awareness is as the important factor in Increasing of customer's tendency in use of Mobile ban

In connection with the second Hypothesis according to the amount of t- statistic that is 2.32 can be said usefulness have Meaningful impact on tend to use of the mobile bank's system. On the other hand the raised route between two variables of awareness and tend to use of mobile bank system Due to the this, is between an independent variable and a dependent variable, is The kind of gamma(0.20) and is Meaningful and Positive

According to the obtained results is specified of this Hypothesis usefulness had positive impact on tend to use of mobile bank system and this thesis is accepted. The obtained result of second Hypothesis is parallel with result of Abushahab (2014) research. Perceived usefulness is noteworthy and important predictors of tend to use of mobile bank .Perceived usefulness has a significant impact on the use of mobile bank that in researches that has been done hitherto, show this subject.Whatever perceived usefulness is more through the mobile bank services, attitude and Intention will be more positive in the direction of the continuous use of these services. So in this way will go up the possibility of use of this system.

In connection to the third Hypothesis, the t-statistic is equal to (2.22) .So this Hypothesis is Meaningful. Therefore is specified that ease have Meaningful impact on tend to use of mobile bank system. On the other hand the raised route between two variables of ease and tend to use of mobile bank system Due to the this, is between an independent variable and a dependent variable, is the kind of gamma (0.19) and is Meaningful and Positive According to the obtained results is specified of this Hypothesisease has positive impact on tend to use of mobile bank system and this Hypothesis is accepted. The obtained result is parallel with 
result of Abushahab (2014) research. Ease of use of mobile bank is defined as influential factor in the use of mobile. Ease of use has direct impact on user's attitude.

Amount of t- statistic of Fourth Hypothesis has been equal to (4.82) so this Hypothesis is meaningful. Therefore is specified Trust to technology having Meaningful impact on trust to mobile bank? On the other hand the raised route between two variables of Trust to technology and trust to mobile bank due to the this, is between an independent variable and a dependent variable, is the kind of gamm (0.42) and is Meaningful and Positive

According to the obtained results is specified of this Hypothesis Trust to technology had positive impact on tend to use of mobile bank and this Hypothesis is accepted. The obtained result is parallel with result of Abushahab (2014) research. Trust is Building block for the success of projects related to e-commerce. Customer's trust is as a set of beliefs that by e-Customer, is in connection with Specifications of e-suppliers.

t- Statistic of Fifth Hypothesis has been equal to (3.09) so can be concluded that this Hypothesis is meaningful .therefore is specified Security have Meaningful impact on trust to mobile bank. On the other hand the raised route between two variables of Security and trust to mobile bank due to the this, is between an independent variable and a dependent variable, is the kind of gamma (0.31) and is Meaningful and Positive

According to the obtained results is specified of this Hypothesis Security had positive impact on trust to mobile bank and this Hypothesis is accepted. The obtained result is parallel with result of Abushahab (2014) research. Security is a form of preservation and maintenance of consumer's trust from invasion and influx to their privacy. Since the security is related with trust strongly, Security norms may give reverse result Such as lost customers, and recommend to others negatively.

t- Statistic of Sixth Hypothesis has been equal to (0.99) so can be concluded that this Hypothesis is not meaningful therefore is specified quality of information have not Meaningful impact on trust to mobile bank. On the other hand the raised route between two variables of quality of information and trust to mobile bank due to it is between an independent variable and a dependent variable, is the kind of gamma (0.99) and is meaningless and positive.

According to the obtained results is specified of this Hypothesis quality of information had not meaningful impact on trust to mobile bank and this Hypothesis is rejected. 
In connection to the Seventh Hypothesis, the t-statistic is equal to (74.6) so can be concluded that this Hypothesis is meaningful. Therefore trust to mobile bank has Meaningful impact on tend to use of mobile bank system. On the other hand the raised route between two variables of trust to mobile bank and tend to use of mobile bank system Due to the this ,is between two dependent variables ,is the kind of $\operatorname{Beta}(0.70)$ and is Meaningful and Positive

According to the obtained results is specified of this Hypothesis trust to mobile bank had positive impact on tend to use of mobile bank system and this Hypothesis is accepted. The obtained result is parallel with result of Abushahab (2014) research.

According to conducted research in this regard shows that exist trust to mobile bank. Therefore the number of mobile bank users increasing every day. Therefore be done effective action in the direction improve and increase of trust especially initial trust to mobile bank.

\section{Suggestions and Limitations of the research}

Trust to technology and security is impacted on trust to mobile bank. So should be done Actions that improve trust to technology. Such as concerns of customer about security issues, informing about the safety, security policies, protect personal information of customer. According to the obtained results, all of variables of research have been appropriated except quality of information on the trust. Therefore, is suggested if possible managers have to think more improvement of research's variables.

Trust to mobile bank has impact on Amount of tend to use of the mobile bank system So any activity that be Leading to increase and Improve of trust, has impact on tend to use , Therefore, should be special attention to trust to mobile bank. Awareness has positive and meaningful impact on tend to use. Customers' awareness can improved through notification by the Bank brochures, advertising and media

Perceived usefulness and ease has also meaningful and positive impact on tend to use Bank officials can increase self- effectiveness of individual in use of Computer and mobile bank systems by holding education Courses.

The following suggestions also to be suggested to future researchers

1. Various factors have different effects on different cultures and each culture must adopt different strategies in dealing with these factors. For example, usefulness is important in one culture and ease in other culture.

2. Should be special attention to subjective norms, perceived image, and personal innovation 
3. Loyalty, readiness, learning will be considered in the direction to use of information technology also should be said that every research is faces with own limitations and present research is not exemption from this matter and existed limitations in this research.

- The first limitation it is that present research has been conducted in one kind of bank and has been not considered as kinds of banks and financial institutions.

- The scope of present research covers use of mobile banks not acceptance and accepts that -Present research has been conducted in a specific time section While to be recommended longitudinal study because the Perception and priorities of people likely to gain More experience will be change during the time.

- Comparison between the old and the young individuals, level of education and also income is effective in the use of mobile bank. That has been not studied these differences

- Another limitation is sample size of study that has been collected to form scope of information from the sample therefore limited size of research is another limitation of the research.

\section{REFERENCES}

1. Amade-H., Jafaepour-M. "explained the obstacles and development of e-banking solutions within the framework of Vision 1404", Journal of Knowledge \& Development, 2009, 26: 43-1.

2. Khaki-Gh.r, "research with an emphasis on thesis writing" Reflections Publishing, printing, 2003.

3. Ghafari Ashtiani-P, "A Framework for Assessment of factors affecting positive oral advertising services market", thesis Business Administration, Islamic Azad University, Tehran research.

4. Konjkavi monfared-AR., Mirhosseini-AA. "Evaluation of factors affecting the acceptance by customers mobile banking branches of Saderat Bank city of Yazd", Journal of Marketing Management, 2013, 18: 120-107.

5. Hashemian-M., Esaei-MT, "Review and identify key factors critical to the acceptance of mobile banking customers," marketing research new, third number, 2011: 108-99.

6. Human-H-A, "Structural equation modeling using LISREL", the publisher, printing, 2005.

7. Abu-Shanab-E, "Antecedents of trust in e-government services: an empirical test in Jordan", Transforming Government: People, Process and Policy, 2014, 8(4): 480-499. 
8. Alawneh-AH., Al-Refai-Kh., Batiha, "Measuring user satisfaction from e-Government services: Lessons from Jordan", Government Information Quarterly 2013, 30: 277-288.

9. Afifa Malina-A., Rashidah-AR., Sharifah, Norzehan Syed Yusof, Intan, Salwani, Mohamed, "The current practice of Islamic microfinance institutions' accounting information system via the implementation of mobile banking", Procedia - Social and Behavioral Sciences 2014, 145: 81 87.

10. Hanafizadeh-P., Behboudi, Abedini Koshksaray-M., Jalilvand, Shirkhani-T, "Mobilebanking adoption by Iranian bank clients", Telematics and Informatics 2014, 31, 62-78.

11. Lee-H., Harindranath-G., Sangjo-Oh, Dong-Jae, Kim, "Provision of mobile banking services from an actor-network perspective: Implications for convergence and standardization", Technological Forecasting \& Social Change, 2015, 90 , 551-561.

12. Lin, Hsiu-Fen, "Determining the relative importance of mobile banking quality factors", Computer Standards \& Interfaces 2013, 35: 195-204.

13. Mohammadi-H, "A study of mobile banking loyalty in Iran", Computers in Human Behavior 2015, 44: 35-47.

How to cite this article:

Zeinabi H, Sheikh M. Evaluate the effect of perceived ease and usefulness,customer's awareness and confidence by mobile bank on tendency to use (intended use) of mobile bank's system (case study of customers of khuzestan's tejarat bankbranches). J. Fundam. Appl. Sci., 2016, 8(2S), 1838-1851. 